ISSN 2089-8673

Jurnal Nasional Pendidikan Teknik Informatika (JANAPATI)

Volume 2, Nomor 1, Maret 2013

\title{
IMPLEMENTASI LINEAR CONGRUENTIAL GENERATOR DALAM RANCANG BANGUN APLIKASI GAME PEDULI LINGKUNGAN
}

\author{
I Putu Gede Budayasa, Gusde Paryatna \\ STMIK STIKOM INDONESIA \\ (gede.budayasa@gmail.com)
}

\begin{abstract}
Abstrak
Hal yang merugikan lingkungan banyak terjadi sehingga diperlukan kesadaran dari setiap orang agar lebih peduli terhadap lingkungan. Dengan demikian maka dampak buruk akibat kondisi lingkungan yang kurang baik dapat dikurangi hingga tidak ada lagi dampak buruk tersebut ke depannya. Menumbuhkan kepedulian terhadap lingkungan harus dimulai sejak usia anak-anak.

Game untuk mengajarkan kepedulian terhadap lingkungan merupakan sebuah permainan yang membuat pemain yang memainkan selalu ingat untuk menjaga lingkungan tetap dalam keadaan baik. Pemainnya diarahkan untuk selalu melakukan hal-hal yang berdampak positif bagi lingkungan terutama dalam kebersihan dan pencegahan terhadap bencana seperti banjir. Tujuan dirancangnya aplikasi game ini adalah untuk memberikan pengetahuan bagaimana menjaga lingkungan agar tetap dalam keadaan baik terutama bagi anak-anak dan menjadikan kebiasaan di kalangan anak-anak untuk tidak melakukan hal yang merugikan lingkungan sehingga terbawa hingga dewasa. Nantinya aplikasi game ini dapat digunakan sebagai media pembelajaran bagi anak-anak.

Rancang bangun game ini menggunakan Microsoft Visual Basic 6.0. Aplikasi ini tidak membutuhkan spesifikasi komputer yang tinggi sehingga mudah digunakan. Metode pembangkit bilangan acak yang diterapkan adalah linear congruential generator (LCG) untuk salah satu proses yang ada di dalam game. Tampilan dari game ini dibuat menarik dengan pemilihan warna yang sesuai dengan karakter anak-anak yang ceria. Dalam aplikasinya game ini diberi nama ñLingkungankuò.

Kata-kunci: Game, Lingkungan, Linear Congruential Generator

\section{Pendahuluan}

Berita tentang banjir sering terdengar dalam kehidupan sehari-hari, bahkan mungkin mengalaminya terutama pada musim hujan. Membuang sampah di sungai adalah salah satu hal yang menyebabkan terjadinya banjir, karena banyaknya sampah di sungai menyebabkan aliran air tidak lancar sehingga banjir terjadi. Itu adalah salah satu contoh bahwa kurang pedulinya terhadap lingkungan dengan membuang sampah di sungai tanpa memikirkankan dampak yang dapat merugikan diri sendiri.
\end{abstract}


ISSN 2089-8673

Jurnal Nasional Pendidikan Teknik Informatika (JANAPATI)

Volume 2, Nomor 1, Maret 2013

Menumbuhkan kepedulian terhadap lingkungan harus dimulai sejak usia dini khususnya anak-anak yang dirasa mampu memahaminya. Untuk menanamkan kepedulian lingkungan terhadap anak, memerlukan pendekatan yang dapat membuat anak tertarik untuk mengikutinya. Salah satunya dengan membuat aplikasi game atau permainan yang disukai anak-anak. Mereka dapat bermain sambil belajar bagaimana menjaga agar lingkungan tetap dalam keadaan baik, dan mengetahui apa saja yang dapat merusak lingkungan sehingga menimbulkan dampak negatif.

Kemajuan teknologi membuat komputer sangat memasyarakat. Mulai dari anakanak hingga orang dewasa menggunakan komputer untuk kebutuhan mereka. Salah satu aplikasi yang terdapat dalam komputer adalah game. Dibuatnya aplikasi game dirasa dapat menarik perhatian anak-anak untuk mencobanya, dan secara tidak langsung memberikan pengetahuan tentang menjaga lingkungan. Meskipun banyaknya game yang ada menggunakan teknologi yang canggih, mulai dari tampilan game dan alat pendukung lainnya, namun game yang sederhana juga menarik untuk dimainkan apalagi dapat berguna sebagai media pembelajaran. Dalam pembuatan sebuah aplikasi game akan diterapkan metode yang dapat membuat aplikasi game ñberjalanò dengan baik. Pemilihan metode disesuaikan dengan kebutuhan aplikasi game tersebut.

\section{Ruang Lingkup}

Aplikasi game yang dibuat hanya sebatas kepedulian terhadap lingkungan yang dapat menyebabkan banjir dan lingkungan menjadi kotor. Metode pembangkit bilangan acak yang diterapkan dalam aplikasi game ini adalah Linear Congruential Generator ( LCG).

\section{Landasan Teori}

Lingkungan adalah faktor-faktor yang membentuk lingkungan sekitar organisme, terutama komponen-komponen yang mempengaruhi perilaku, reproduksi, dan kelestarian organisme (Neolaka, 2008).

Game merupakan kata dalam bahasa inggris bila diterjemahkan ke dalam bahasa indonesia berarti permainan. Game komputer adalah permainan yang dimainkan pada 
ISSN 2089-8673

Jurnal Nasional Pendidikan Teknik Informatika (JANAPATI)

Volume 2, Nomor 1, Maret 2013

komputer. Memainkan game di komputer sangat menyenangkan. Namun demikian, akan lebih menyenangkan lagi bila berhasil membuat game dan kemudian melihat orang lain memainkannya. Membuat game memang tidak mudah. Beberapa game komersial yang pernah dimainkan, misalnya dibuat dan dikembangkan oleh banyak orang dengan keahlian pemrograman yang tinggi dan dibuat dengan biaya yang relatif besar (Wibawanto, 2006).

Linear Congruential Generator atau jika diubah kedalam bahasa Indonesia menjadi Pembangkit Bilangan Acak Kongruen-Lanjar merupakan pembangkit bilangan acak yang sederhana, mudah dimengerti teorinya, dan juga mudah untuk diimplementasikan. LCG didefinisikan dalam relasi berulang berikut :

$X_{n}=\left(a X_{n} \ddot{\mathrm{i} l}+b\right) \bmod m$

Dimana :

$\mathrm{X}_{\mathrm{n}} \quad=$ bilangan acak ke-n dari deretnya

$\mathrm{X}_{n-1} \quad=$ bilangan acak sebelumnya

$a \quad=$ faktor pengali

$b \quad=$ increment

$m \quad$ = modulus

$\mathrm{X}_{0}$ adalah kunci pembangkit atau disebut juga umpan (seed). LCG mempunyai periode tidak lebih besar dari m, dan pada kebanyakan kasus periodenya kurang dari itu. LCG mempunyai periode penuh ( $m \ddot{\mathrm{I}}$ 1) jika memenuhi syarat berikut:

- $b$ relatif prima terhadap $m$.

- $\quad a \ddot{~} 1$ dapat dibagi dengan semua faktor prima dari $m$

- $\quad a \ddot{~} 1$ adalah kelipatan 4 jika m adalah kelipatan 4

- $\quad m>\operatorname{maks}\left(a, b, \mathrm{X}_{0}\right)$

- $a>0, b>0$

Keunggulan LCG terletak pada kecepatannya dan hanya membutuhkan sedikit operasi bit. 
ISSN 2089-8673

Jurnal Nasional Pendidikan Teknik Informatika (JANAPATI)

Volume 2, Nomor 1, Maret 2013

\section{Perancangan Aplikasi}

Game yang dirancang bernama ñLingkungankuò berbasis desktop aplication. Nama tersebut menggambarkan bahwa permainan yang akan dimainkan berhubungan dengan lingkungan. Yang menjadi sasaran pengguna aplikasi game ini adalah anakanak. Tentu saja mereka yang sudah bisa membaca dan mengoprasikan komputer. Dalam game ini tampilan yang dipilih bernuansa modern dengan warna-warna beragam yang cenderung disenangi anak-anak. Warna utama yang dipilih adalah hijau. Hijau adalah warna yang cenderung menggambarkan alam, lingkungan, alami. Warna hijau akan dikombinasikan dengan warna lain, sehingga terkesan ceria. Berdasarkan klasifikasi dari game PC, game ini termasuk role play game (RPG) yang memainkan peran suatu karakter dalam menjalankan misi tertentu.

\subsection{Halaman Game Utama}

Halaman ini terdiri dari:

1. Papan permainan yang terdiri dari 40 kotak. Setiap kotak berisi nomor serta beberapa yang berisikan peraturan atau pemberitahuan yang berbeda tentang apa yang akan terjadi selanjutnya pada pemain. Misalnya, pada kotak delapan berisi pemberitahuan untuk menambahkan satu poin kepada pemain yang berhenti pada posisi tersebut atau pada kotak keempat yang mengharuskan pemain yang berhenti disana untuk mendapatkan kartu merah.

2. Angka satu sampai dengan 10 diputar secara cepat bila tombol ñputarò ditekan, dan dihentikan oleh pemain dengan menekan tombol ñberhentiò sehingga muncul salah satu angka. Angka tersebut menunjukkan berapa langkah pemain harus melangkah pada papan.

3. Tombol ñputaròuntuk memutar angka.

4. Tombol f̃ berhentiò untuk menghentikan putaran angka.

5. Poin adalah nilai yang diperoleh oleh pemain. Fungsi dari poin pemain adalah untuk memberikan motivasi bagi pemain agar mengumpulkan sebanyakbanyaknya poin tersebut. Poin bisa bertambah atau berkurang sesuai kondisi 
yang didapatkan pemain saat mendapat giliran. Poin awal yang diberikan adalah 25.

6. Menu keluar untuk keluar dari permainan.

7. Kartu merah atau hijau yang berisi perintah atau pemberitauan kepada pemain apa yang harus dilakukan yang dapat mempengaruhi poin pemain selanjutnya. Kartu merah berisi perintah atau pemberitahuan yang kurang menyenangkan bagi pemain. Misalnya, ñPoin anda akan dikurangi dua karena anda telah membuang sampah sembarangan!ò. Maka poin pemain yang mendapat kartu ini akan dikurangi dua. Sebaliknya, kartu hijau berisi perintah atau pemberitahuan yang menyenangkan bagi pemain.

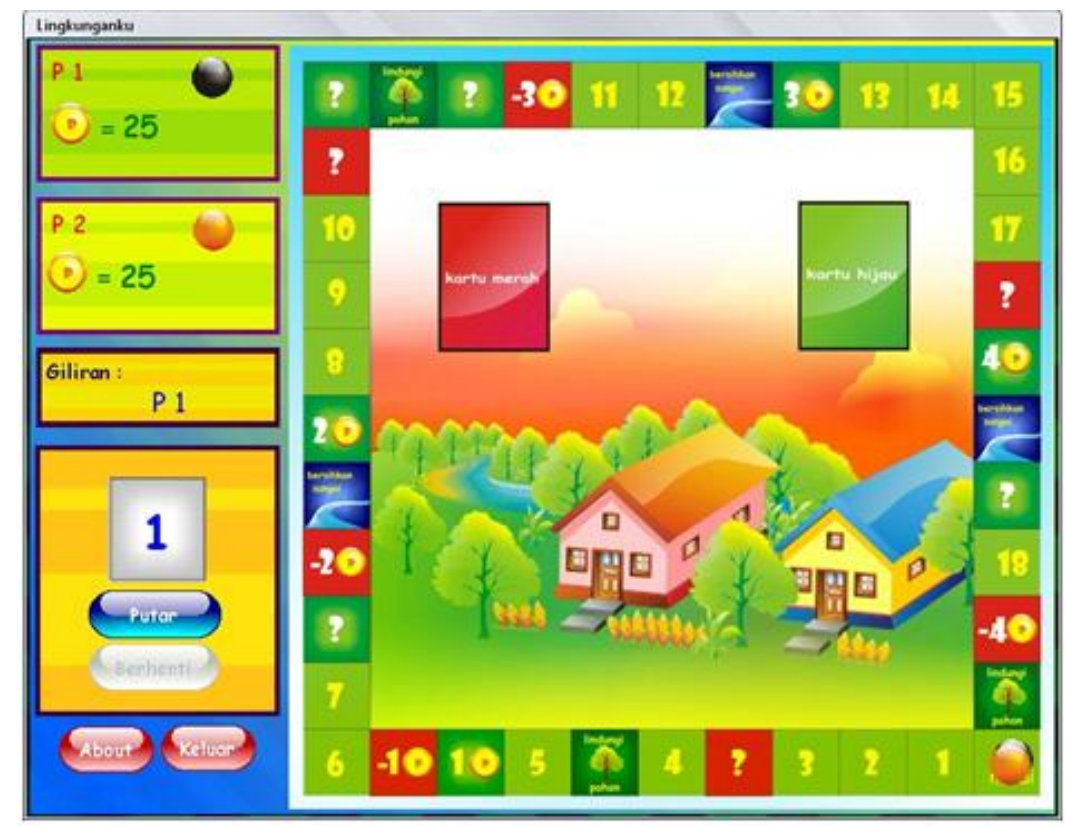

Gambar 1. Halaman Game Utama

Halaman game utama ini menggunakan Linear Congruential Generator (LCG) untuk menampilkan kartu merah dan kartu hijau secara acak. Ada 10 kartu yang akan diacak kemunculannya. Masing-masing 10 kartu dari kartu merah dan juga 10 kartu dari kartu hijau. 
ISSN 2089-8673

Jurnal Nasional Pendidikan Teknik Informatika (JANAPATI)

Volume 2, Nomor 1, Maret 2013

$\mathrm{X}_{n}=\left(a \mathrm{X}_{n \ddot{1} 1}+b\right) \bmod m$

$\mathrm{X}_{n}=\left(2 \mathrm{X}_{n} \ddot{1} 1+5\right) \bmod 11$ dengan $\mathrm{X}_{0}=0$

$\mathrm{X} 1=(2 \mathrm{X} 1 \ddot{1} 1+5) \bmod 11=(2 \mathrm{X} 0+5) \bmod 11=(2.0+5) \bmod 11=5 \bmod 11=5$

$\mathrm{X} 2=(2 \mathrm{X} 2 \mathrm{i} 1+5) \bmod 11=(2 \mathrm{X} 1+5) \bmod 11=(2.5+5) \bmod 11=15 \bmod 11=4$

$\mathrm{X} 3=(2 \mathrm{X} 3 \ddot{\mathrm{I}} 1+5) \bmod 11=(2 \mathrm{X} 2+5) \bmod 11=(2.4+5) \bmod 11=5 \bmod 11=2$

$\mathrm{X} 4=(2 \mathrm{X} 4 \ddot{1} 1+5) \bmod 11=(2 \mathrm{X} 3+5) \bmod 11=(2.2+5) \bmod 11=5 \bmod 11=9$

$\mathrm{X} 5=(2 \mathrm{X} 5 \ddot{1} 1+5) \bmod 11=(2 \mathrm{X} 4+5) \bmod 11=(2.9+5) \bmod 11=5 \bmod 11=1$

$\mathrm{X} 6=(2 \mathrm{X} 6 \ddot{1} 1+5) \bmod 11=(2 \mathrm{X} 5+5) \bmod 11=(2.1+5) \bmod 11=5 \bmod 11=7$

$\mathrm{X} 7=(2 \times 7 \ddot{1} 1+5) \bmod 11=(2 \mathrm{X} 6+5) \bmod 11=(2.7+5) \bmod 11=5 \bmod 11=8$

$\mathrm{X} 8=(2 \mathrm{X} 8 \ddot{\mathrm{I}} 1+5) \bmod 11=(2 \mathrm{X} 7+5) \bmod 11=(2.8+5) \bmod 11=5 \bmod 11=10$

$\mathrm{X} 9=(2 \mathrm{X} 9 \ddot{\mathrm{I}} 1+5) \bmod 11=(2 \mathrm{X} 8+5) \bmod 11=(2.10+5) \bmod 11=5 \bmod 11=3$

$\mathrm{X} 10=(2 \mathrm{X} 10 \mathrm{I} 1+5) \bmod 11=(2 \mathrm{X} 9+5) \bmod 11=(2.3+5) \bmod 11=5 \bmod 11=0$

$\mathrm{X} 11=(2 \mathrm{X} 11 \mathrm{i} 1+5) \bmod 11=(2 \mathrm{X} 10+5) \bmod 11=(2.0+5) \bmod 11=5 \bmod 11=$ 5

$\mathrm{X} 12=(2 \mathrm{X} 12 \ddot{\mathrm{i}} 1+5) \bmod 11=(2 \mathrm{X} 11+5) \bmod 11=(2.5+5) \bmod 11=5 \bmod 11=$ 4

Tabel 1.Hasil Perhitungan Linear Congruential Generator

\begin{tabular}{|c|c|}
\hline $\mathrm{N}$ & $\mathrm{Xn}$ \\
\hline 0 & 0 \\
\hline 1 & 5 \\
\hline 2 & 4 \\
\hline 3 & 2 \\
\hline 4 & 9 \\
\hline 5 & 1 \\
\hline 6 & 7 \\
\hline 7 & 8 \\
\hline 8 & 10 \\
\hline 9 & 3 \\
\hline 10 & 0 \\
\hline 11 & 5 \\
\hline 12 & 4 \\
\hline
\end{tabular}


ISSN 2089-8673

Jurnal Nasional Pendidikan Teknik Informatika (JANAPATI)

Volume 2, Nomor 1, Maret 2013

Sesuai dengan $\mathrm{a}=2, \mathrm{~b}=5, \mathrm{~m}=11$ dan $\mathrm{X}_{0}=0$ didapatkan $\mathrm{X} 1=5$ dan seterusnya sehingga, didapatkan bilangan acak sampai 10 periode. Bilangan acak tersebut didalam aplikasi game akan dijadikan acuan untuk menampilkan sebanyak 10 kartu secara acak. Misalnya, X1 = 5 menunjukkan bahwa kartu yang akan tampil adalah kartu yang kelima. Khusus untuk kartu yang keenam akan muncul ketika Xn $=0$. Karena terdapat dua jenis kartu, maka akan membuat kartu yang muncul semakin acak. Pemain tidak mengetahui urutan nomor kartu merah atau hijau.

Perintah atau pemberitahuan pada kartu merah :

1. Anda mengotori sungai! Poin dikurangi 2.

2. Anda melakukan penebangan liar! Poin dikurangi 3.

3. Anda membuang sampah di jalan! Poin dikurangi 1.

4. Cegah penebangan pohon liar!

5. Bersihkan sungai dari sampah!

6. Anda tidak berpartisipasi dalam gerakan kebersihan lingkungan! Poin dikurangi 2.

7. Anda membiarkan saluran air tersumbat sampah! Poin dikurangi 2.

8. Anda membuang bungkus permen sembarangan! Poin dikurangi 2.

9. Anda membiarkan halaman rumah anda kotor! Poin dikurangi 1.

10. Anda membuang sampah di sungai sehingga banjir! Poin dikurangi 2.

Perintah atau pemberitahuan pada kartu hijau :

1. Anda telah membersihkan sungai dari sampah! Poin ditambah 2.

2. Anda telah membuang sampah pada tempatnya! Poin ditambah 3.

3. Anda telah berpartisipasi dalam gerakan menanam pohon! Poin ditambah 2.

4. Cegah penebangan pohon liar!

5. Bersihkan sungai dari sampah!

6. Anda telah membantu membersihkan saluran air! Poin ditambah 1.

7. Anda sudah berpartisipasi dalam gerakan kebersihan lingkungan! Poin ditambah 3. 
8. Anda telah berhasil memimpin masyarakat untuk membersihkan lingkungan! Poin ditambah 2.

9. Anda sudah menjaga halaman rumah anda tetap bersih dari sampah! Poin ditambah 1.

10. Anda membantu mengatasi banjir, dengan menjaga kebersihan sungai! Poin ditambah 2.

\subsection{Permainan Mencegah Penebangan Pohon}

Permainan ini akan muncul ketika pemain berada pada salah satu posisi atau kotak pada papan permainan yang mengharuskan pemain tersebut memainkan permainan mencegah penebangan pohon ini. Game ini berisi tombol arah kiri dan kanan untuk menggeser penghalang, penebang liar yang muncul tiba-tiba dan terdapat pohon yang harus dilindungi dari penebang liar. Permainan dimulai dengan menekan tombol mulai. Selama batas waktu 10 detik, penebang liar muncul tiba-tiba dari tiga posisi, yaitu tengah, kiri dan kanan secara acak. Apabila penebang liar lolos dari penghalang, maka poin pemain dikurangi satu, sebaliknya apabila berhasil dihalangi untuk menebang pohon maka poin ditambah satu. Dimana poin awal ketika permainan ini dimulai adalah nol. Ketika permainan ini sudah berakhir, poin yang didapat pada permainan ini akan dijumlahkan dengan poin utama pemain.

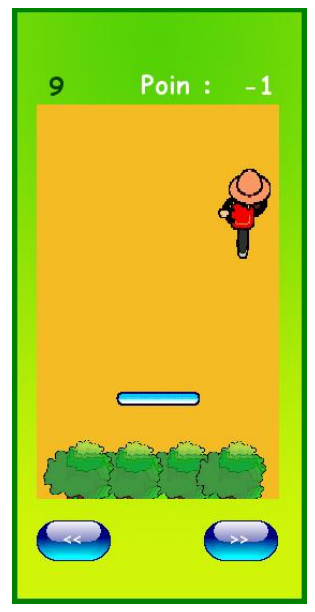

Gambar 2. Permainan Mencegah Penebangan Pohon 
ISSN 2089-8673

Jurnal Nasional Pendidikan Teknik Informatika (JANAPATI)

Volume 2, Nomor 1, Maret 2013

\subsection{Permainan Membersihkan Sungai}

Permainan ini akan muncul ketika pemain berada pada salah satu posisi atau kotak pada papan permainan yang mengharuskan pemain tersebut memainkan permainan membersihkan sungai. Game ini berisi tombol arah kiri dan kanan untuk menggeser jaring sampah dan terdapat sampah yang muncul tiba-tiba. Permainan dimulai dengan menekan tombol mulai. Selama batas waktu 10 detik, sampah yang hanyut muncul tiba-tiba dari tiga posisi, yaitu tengah, kiri dan kanan secara acak. Apabila sampah lolos dari jaring sampah, maka poin pemain dikurangi satu, sebaliknya apabila sampah berhasil dijaring maka poin ditambah satu. Dimana poin awal ketika permainan ini dimulai adalah nol. Ketika permainan ini sudah berakhir, poin yang didapat pada permainan ini akan dijumlahkan dengan poin utama pemain.

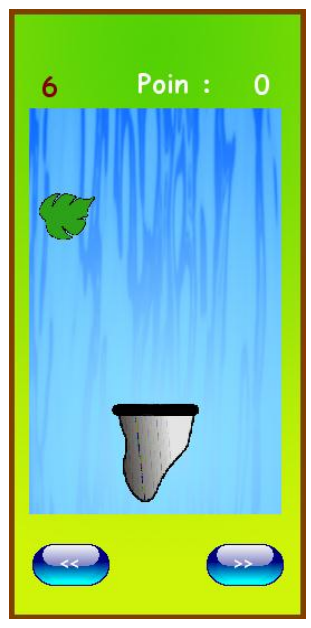

Gambar 3. Permainan Membersihkan Sungai

\section{Kesimpulan}

Aplikasi game dengan nama Lingkunganku berhasil dibuat dan dapat digunakan sebagai media pembelajaran bagi anak-anak khususnya untuk menjaga lingkungan seperti mengurangi ancaman banjir dan dampak buruk akibat sampah.

Linear Congruential Generator (LCG) dapat digunakan dalam aplikasi game Lingkunganku pada proses pengacakan kartu. Proses pengacakan dengan metode Linear Congruential Generator (LCG) akan mudah ditebak jika nilai pembangkit $\left(\mathrm{X}_{0}\right)$ tetap 
ISSN 2089-8673

Jurnal Nasional Pendidikan Teknik Informatika (JANAPATI)

Volume 2, Nomor 1, Maret 2013

sama ketika mengawali proses pengacakan, namun bila $\mathrm{X}_{0}$ tidak bernilai sama akan sulit ditebak dan metode ini akan semakin acak bila digunakan untuk mengacak lebih dari satu objek sekaligus, dimana pada aplikasi game ini objeknya adalah kartu merah dan kartu hijau.

\section{DAFTAR PUSTAKA}

Kusrianto, Adi. 2007. Pengantar Desain Komunikasi Visual. Yogyakarta : Andi

Neolaka, Amos. 2008. Kesadaran Lingkungan. Jakarta : Rineka Cipta.

Nugroho, Eko. 2008. Teori Warna. Yogyakarta : Andi

Oviyanto, Fendi. 2009. Desktop Application. www.sainstech.com. Diakses pada tanggal 14 Desember 2011.

Ruswan Putranto, Yohanes Andika. 2010. Pengembangan Teknik Pembangkitan Bilangan Acak Berbasiskan Hardware. http://www.informatika.org/ rinaldi/Kriptografi/20092010/Makalah2/Makalah2_IF3058_2010_031.pdf. Diakses pada tanggal 12 Desember 2011.

Ramadhan, Andresta. 2007. Perbandingan Algoritma Linear Congruential Generators, BlumBlumShub, dan MersenneTwister untuk Membangkitkan Bilangan Acak Semu. www.informatika.org/ rinaldi/kriptografi/2006-2007/makalah2 /makalah005.pdf. Diakses pada tanggal 12 Desember 2011.

Suyanto. 2005. Multimedia untuk Meningkatkan Keunggulan Bersaing. Yogyakarta : Andi.

Wibawanto, Wandah. 2006. Membuat Game dengan Macromedia Flash. Yogyakarta : Andi. 